Neurovascular, Fremont, CA, USA) in the treatment of small intracranial aneurysms.

Methods The ULTRA Registry is a prospective database of patients with small $(<5 \mathrm{~mm})$ intracranial aneurysms treated exclusively with Target ${ }^{\circledR}$ Ultrasoft and Nano coils. The primary endpoints are target aneurysm re-intervention or target aneurysm rupture during follow up, and secondary endpoints include residual aneurysm rates and device related or procedural adverse events.

Results 100 patients (75\% female; mean age 57.1 [SD 11.7]; 48 ruptured) were treated from December 2013 to January 2019. Stent and balloon assistance was used in 21 and 19 cases, respectively. No flow diverting stents were used. Mean aneurysm size was $3.5 \times 3.0 \times 2.8 \mathrm{~mm}$ (SD $0.9 \times 1 \times 0.9$ $\mathrm{mm}$, respectively), and mean neck size was $2 \mathrm{~mm}$ (SD 0.7 $\mathrm{mm})$. Mean number of coils placed in each aneurysm was 2.9 (SD 1.6), and mean packing density was 34.3\% (SD 16.6). First follow up imaging was MRA in 50 cases and DSA in 28 cases (mean 5.7 months [SD 2.4]), and second follow up imaging was DSA in 60 cases and MRA in 2 cases (mean 14.7 months [SD 5.6]). Residual aneurysm on the Raymond Roy Scale per investigator and core lab reporting was present at baseline post-coiling, $1^{\text {st }}$ imaging follow up, and $2^{\text {nd }}$ imaging follow up in $3 \%$ and $8 \%, 9 \%$ and $12.8 \%$, and $11.3 \%$ and $12.9 \%$, respectively. Aneurysm recurrence by investigator report and core lab report was $12.8 \%$ and $14.3 \%$, respectively, on first follow up and $17.7 \%$ and $21 \%$, respectively, on second follow up. Aneurysms requiring retreatment by investigator report and core lab report were $10.3 \%$ and $10.4 \%$, respectively, on first follow up and $9.7 \%$ and $11.3 \%$, respectively, on second follow up. Of 9 retreated aneurysms, 8 presented as a rupture. Including both retreated aneurysms as well as those deemed as requiring retreatment, retreatment and/or need for retreatment at final imaging follow up was $18.8 \%$ per investigator report and $20.3 \%$ per core lab report. There were worse occlusion grades, higher rates of recurrence, greater need for retreatment, and more serious adverse events in ruptured vs unruptured aneurysms at $1^{\text {st }}$ and $2^{\text {nd }}$ follow up. There were 0 coil related complications, 0 intraoperative aneurysm ruptures, and 0 known post-operative aneurysm ruptures. There were 7 procedural related adverse events: ischemic stroke $(n=3)$, intracranial hemorrhage from wire perforation of the anterior cerebral artery distant to and not involved by aneurysm $(n=1)$, cellulitis $(n=1)$, groin hematoma $(\mathrm{n}=1)$, lip numbness $(\mathrm{n}=1)$.

Conclusions The ULTRA Registry demonstrates excellent safety and efficacy profiles of Target ${ }^{\circledR}$ Ultrasoft and Nano coils in the treatment of ruptured and unruptued small intracranial aneurysms with no coil related complications in the study.
Disclosures G. Jindal: 1; C; Microvention, Stryker Neurovascular. R. Almardawi: None. D. Gandhi: 1; C; Microvention, InsightTech. T. Miller: 1; C; Vesalio, Microvention. S. Satti: 2; C; Cerenovus, Balt, Cerenovus, Medtronic, Stryker, Terumo, Penumbra, Q’Apel. F. Hui: None.

\section{P-059 RACE AS A SOCIAL DETERMINANT OF POOR OUTCOMES FOLLOWING UNRUPTURED ANEURYSM SURGERY}

S Koester*, A Yengo-Kahn, M Feldman, M Lan, P Patel, A Churchwell, R Chitale Neurologic Surgery, Vanderbilt University Medical Center, Nashville, TN

\subsection{6/neurintsurg-2021-SNIS.95}

Introduction Racial disparities have been documented across medical fields including stroke. However, the extent and consequence of disparities in the care of cerebral aneurysms is incompletely defined. Our objective was to determine whether racial disparities exist in the outcomes following unruptured aneurysm repair.

Methods Data from the 2012-2015 National Inpatient Sample (NIS) database was analyzed. Patients who underwent either open or endovascular treatment of unruptured intracranial aneurysms were included $(\mathrm{n}=11663)$. Patients missing race data, those of super-minority $(\mathrm{n}<100)$ race $(\mathrm{n}=1202)$, and those admitted with concurrent head trauma ( $\mathrm{n}=110)$ or AVM ( $\mathrm{n}=71$ ) were excluded. The exposure of interest was race. The primary outcome was occurrence of a poor outcome, defined as occurrences of one or more of: in-hospital mortality, discharge to a nursing facility or hospice, placement of a tracheostomy tube, or placement of a gastrostomy tube. Secondary outcomes were hospital length of stay and any complication experienced (i.e. surgical, infectious, medical). Multivariate logistic and linear regression was performed for each outcome correcting for potentially confounding variables such as age, sex, procedural type, elective procedure, obesity, diabetes, tobacco, severity of illness, and hospital type. Given the number of comparisons, statistical significance was a priori defined as $\mathrm{p}<0.01$.

Results 7478 White, 1460 Black, 1086 Hispanic, and 279 Asian patients were included in the final analysis. Black patients experienced the greatest rate of complications (24\%) and poor outcomes (13\%). After adjusting for confounding variables, Black patients demonstrated greater odds of poor outcomes (OR: 1.32; 95\% CI: 1.07, 1.62; p = 0.008) compared to White patients. Black (B: 0.04; 95\% CI: 0.03, 0.06; p <0.001) and Hispanic (B: 0.04; 95\% CI: 0.02, 0.05; p

Abstract P-059 Table 1 Outcomes

\begin{tabular}{|c|c|c|c|c|}
\hline Characteristic & White, $N=7,478$ & Black, $N=1,460$ & Hispanic, $N=1,086$ & Asian, $\mathrm{N}=279$ \\
\hline Any Complication & $1,599(21 \%)$ & $355(24 \%)$ & $255(23 \%)$ & $58(21 \%)$ \\
\hline Surgical Complication & $913(12 \%)$ & $191(13 \%)$ & $128(12 \%)$ & $29(10 \%)$ \\
\hline Poor Outcome & $954(13 \%)$ & $257(18 \%)$ & $140(13 \%)$ & $34(12 \%)$ \\
\hline Tracheostomy Tube Placed & $92(1.2 \%)$ & $44(3.0 \%)$ & $17(1.6 \%)$ & $6(2.2 \%)$ \\
\hline Gastrostomy Tube Placed & $128(1.7 \%)$ & $48(3.3 \%)$ & $24(2.2 \%)$ & $7(2.5 \%)$ \\
\hline Died & $101(1.4 \%)$ & $19(1.3 \%)$ & $17(1.6 \%)$ & $5(1.8 \%)$ \\
\hline Length of Stay & $4.6(6.9)$ & $6.5(9.7)$ & $6.0(8.7)$ & $6.4(13.9)$ \\
\hline
\end{tabular}

Statistics presented: $\mathrm{n}(\%)$; Mean (SD)Statistical tests performed: chi-square test of independence; Wilcoxonrank-sum test; Fisher's exact test 
Abstract P-059 Table 2 Adjusted outcomes

\begin{tabular}{|c|c|c|c|c|c|c|c|c|c|}
\hline \multirow[b]{2}{*}{ Factor } & \multicolumn{3}{|c|}{ Poor Outcome } & \multicolumn{3}{|c|}{ Length of Stay } & \multicolumn{3}{|c|}{ Any Complication } \\
\hline & $\mathrm{OR}$ & $95 \% \mathrm{Cl}$ & $P$ & $\exp ($ Beta, B) & $95 \% \mathrm{Cl}$ & $P$ & OR & $95 \% \mathrm{Cl}$ & $P$ \\
\hline Race & 1.32 & $1.07,1.62$ & 0.008 & 0.04 & $0.03,0.06$ & $<0.001$ & 0.94 & $0.80,1.10$ & 0.4 \\
\hline Black & 0.77 & $0.60,0.99$ & 0.043 & 0.04 & $0.02,0.05$ & $<0.001$ & 1.02 & $0.85,1.23$ & 0.8 \\
\hline Hispanic & 0.6 & $0.42,1.09$ & 0.12 & 0.02 & $0.01,0.05$ & 0.2 & 0.81 & $0.56,1.15$ & 0.2 \\
\hline Asian & REF & - & - & REF & - & - & REF & - & - \\
\hline \multicolumn{10}{|l|}{ White } \\
\hline Age & 1.04 & $1.04,1.05$ & $<0.001$ & -0.01 & $-0.05,0.04$ & 0.8 & 1.01 & $1.00,1.01$ & $<0.001$ \\
\hline Sex & 1.11 & $0.94,1.31$ & 0.2 & 0.01 & $0.00,0.02$ & 0.044 & 1.25 & $1.10,1.43$ & $<0.001$ \\
\hline Female & REF & - & - & REF & - & - & REF & - & - \\
\hline \multicolumn{10}{|l|}{ Male } \\
\hline Clip & 2.15 & $1.83,2.52$ & $<0.001$ & 0.27 & $0.26,0.28$ & $<0.001$ & 0.77 & $0.68,0.87$ & $<0.001$ \\
\hline Elective & 0.67 & $0.57,0.80$ & $<0.001$ & -0.30 & $-0.32,-0.29$ & $<0.001$ & 1.16 & $1.01,1.33$ & 0.032 \\
\hline Obese & 1.13 & $0.90,1.40$ & 0.3 & 0.00 & $-0.01,0.02$ & 0.8 & 0.95 & $0.80,1.13$ & 0.6 \\
\hline Diabetic & 1.34 & $1.10,1.64$ & 0.004 & 0.00 & $-0.02,0.01$ & 0.9 & 1.20 & $1.02,1.40$ & 0.025 \\
\hline Tobacco & 0.85 & $0.72,1.01$ & 0.071 & 0.00 & $-0.01,0.01$ & $>0.9$ & 0.96 & $0.85,1.09$ & 0.6 \\
\hline Severity of IIIness & 190 & 130,286 & $<0.001$ & 0.78 & $0.76,0.80$ & $<0.001$ & 68.6 & $54.5,86.6$ & $<0.001$ \\
\hline Extreme & 26.1 & $18.1,38.9$ & $<0.001$ & 0.46 & $0.45,0.48$ & $<0.001$ & 16.7 & $13.7,20.3$ & $<0.001$ \\
\hline Major & 4.96 & $3.43,7.41$ & $<0.001$ & 0.14 & $0.13,0.15$ & $<0.001$ & 3.97 & $3.33,4.76$ & $<0.001$ \\
\hline Moderate & REF & - & - & REF & - & - & REF & - & - \\
\hline \multicolumn{10}{|l|}{ Minor } \\
\hline Hospital Status & 0.64 & $0.22,2.16$ & 0.4 & -0.11 & $-0.19,-0.02$ & 0.015 & 2.04 & $0.71,6.94$ & 0.2 \\
\hline Urban Teaching & 0.75 & $0.25,2.60$ & 0.6 & -0.11 & $-0.20,-0.02$ & 0.013 & 2.23 & $0.77,7.68$ & 0.2 \\
\hline Urban Non-Teaching & REF & - & - & REF & - & - & REF & - & - \\
\hline Rural & & & & & & & & & \\
\hline
\end{tabular}

$<0.001)$ patients experienced slightly longer length of stay compared to White patients. The odds of experiencing any complication were similar across races.

Conclusion In this nationwide analysis, racial disparities were present in that Black patients were at increased odds of poor outcomes and both Black and Hispanic patients experience longer lengths of stay when compared to White patients after adjusting for several possible confounding factors. In the shared effort to provide equitable care, an important first step is analyzing and acknowledging the differences in objective outcomes as racial disparities in neurosurgery. Understanding the specific factors underlying the differences, such as possible differences in care access, is the next step to improve health equity in cerebrovascular neurosurgery.

Disclosures S. Koester: None. A. Yengo-Kahn: None. M. Feldman: None. M. Lan: None. P. Patel: None. A. Churchwell: None. R. Chitale: None.

\section{P-060 APPLICATION OF NON-DESTRUCTIVE MECHANICAL CHARACTERIZATION TESTING FOR CREATING IN VITRO VESSEL MODELS WITH MATERIAL PROPERTIES SIMILAR TO HUMAN NEUROVASCULATURE}

K Lewis*, J Vigil, N Norris, W Merritt, T Becker. Mechanical Engineering: Bioengineering Program Mechanical Engineering (ME), Northern Arizona University, Flagstaff, AZ

\subsection{6/neurintsurg-2021-SNIS.96}

Introduction/Purpose Vessel models are a first step in developing endovascular medical devices. These models are often madefrom glass or silicone, which do not accurately represent the mechanical properties of human vasculartissue, limiting their use to basic training and proof-of-concept testing. This study outlines methods toquantify the mechanical properties of both human vascular tissue and synthetic biomaterials for creatingrepresentative vessel models.
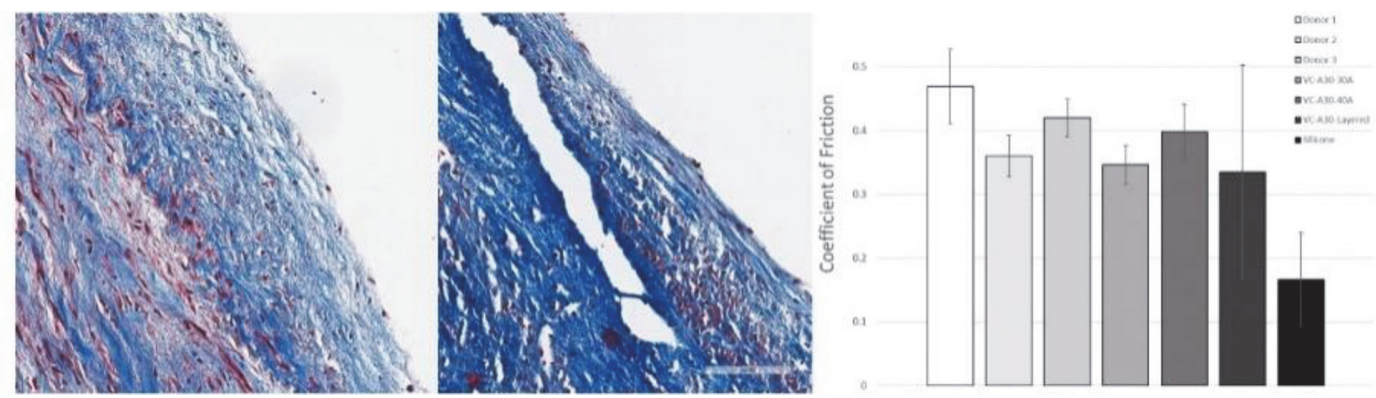

Abstract P-060 Figure 1 Left - non-destructive mechanical testing of human tissue. No disruption of tunica or endothelial layer. Middle destructive mechanical testing, apparent tunica and endothelial disruptions. Right - coefficient of friction lubricity of the human donor, compared to VC-A30 (dark gray) and silicone (black) 